\title{
Liderança e Comportamento Organizacional: uma Relação Intrínseca na Gestão
}

\section{Leadership and Organizational Behavior: an Intrinsic Relationship in Management}

\author{
Francisco Sousa da Silva*; Maika Rodrigues Amorimb \\ ${ }^{a}$ Faculdade Pitágoras de Imperatriz, Pós-Graduação Lato Sensu em Administração Integrada. MA, Brasil.

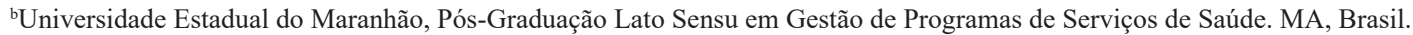 \\ *E-mail: francisco.economia@bol.com.br
}

\begin{abstract}
Resumo
O presente artigo tem como objetivo discutir sobre comportamento organizacional e liderança, bem como a relação existente entre as duas temáticas. A metodologia utilizada foi de cunho bibliográfico, fundamentada em livros e artigos científicos já publicados sobre o tema em questão. Para tanto, foi abordado o comportamento organizacional, seus modelos, habilidades e competências, bem como as teorias mais conhecidas sobre a temática em questão. Inicialmente, foi realizado um levantamento bibliográfico. Ao abordar a temática: Comportamento Organizacional e Liderança é impreterível abordar as relações de pessoas, no ambiente organizacional, uma vez que esse é composto por pessoas, dando-lhe vida e personalidade própria, porém a maneira por meio da qual as pessoas se comportam, tomam decisões, trabalham, varia de diferentes formas, sendo que tal variação vai depender, em sua maioria, das políticas e diretrizes das organizações na maneira como lidar com as pessoas em suas atividades. Para mobilizar e utilizar toda a capacidade das pessoas, em suas atividades, as organizações têm buscado modificar seus conceitos, alterando suas práticas gerenciais, investindo diretamente nas pessoas, que entendem dos produtos e serviços, em vez de focar somente nos clientes. Do exposto se conclui que os estilos de liderança possuem estreita relação com o comportamento organizacional, conclui-se ainda que a figura do líder é fundamental dentro desses arranjos do comportamento organizacional, liderando as pessoas, as equipes para que essas possam desenvolver suas atividades em consonância com os interesses da organização.
\end{abstract}

Palavras-chave: Comportamento Organizacional. Liderança. Relações Interpessoais.

\begin{abstract}
This article aims to discuss organizational behavior and leadership, as well as the relationship between the two themes. The methodology used was bibliographic, based on books and scientific articles already published on the subject in question. For this, the organizational behavior, its models, skills and competences, as well as the most well-known theories on the subject matter were approached. When addressing the theme: Organizational Behavior and Leadership, it is imperative to approach the people's relationships in the organizational environment, since it is composed of people, giving it life and personality, but the way people behave, take decisions, work, varies in different ways, and such variation will depend, for the most part, on the policies and guidelines of the organizations on how to deal with people in their activities. In order to mobilize and utilize all the people's capacity in their activities, organizations have sought to modify their concepts, changing their managerial practices, investing directly in the people who understand the products and services instead of focusing only on the clients.From the foregoing, it is concluded that leadership styles are closely related to organizational behavior, it is also concluded that the leader is fundamental within these arrangements of organizational behavior, leading people, and the teams so that they can develop their activities in line with the interests of the organization.
\end{abstract}

Keywords: Organizational Behavior. Leadership. Interpersonal Relationships.

\section{Introdução}

O trabalho aqui apresentado se estrutura da seguinte maneira: inicialmente se aborda a temática do Comportamento Organizacional seus meandros e relação com a questão da Liderança.

No terceiro tópico serão apresentadas as teorias relacionadas com a Liderança, suas características, estilos e modelos.

No quarto tópico são apresentadas as considerações finais do trabalho, que têm o objetivo de estabelecer uma discussão sobre o comportamento organizacional e liderança, observando as inter-relações entre as duas temáticas. Demonstrando assim, a importância de entender como esses dois fatores interferem, ao mesmo tempo, em que são fundamentais para o desenvolvimento das organizações.

$\mathrm{O}$ comportamento organizacional está relacionado às atividades desenvolvidas no campo de trabalho e por meio do conhecimento deste é possível obter algumas respostas para melhor intervir no ambiente organizacional. Dessa forma, é oportuno analisar os elementos responsáveis pelo desenvolvimento da cultura organizacional, a forma como esses são trabalhados e, ainda, as mudanças que esses provocam no desempenho organizacional.

\section{Desenvolvimento}

\subsection{Comportamento Organizacional}

O comportamento organizacional pode ser considerado como uma área de estudos com a finalidade de pesquisar 
as ações causadas por indivíduos, equipes e a forma que a estrutura tem sobre o desempenho dentro das empresas (ROBBINS, 2010).
Chiavenato
(2010,
p.6) define
o comportamento organizacional como:

[...] estudo de indivíduos e grupos atuando em organizações. Preocupa-se com a influência das pessoas e grupos sobre as organizações e, vice-versa, com a influência das organizações sobre as pessoas e grupos. Na realidade, o comportamento organizacional retrata a contínua interação entre pessoas e organizações que se influenciam reciprocamente. Constitui uma importante área de conhecimento para toda pessoa que necessite lidar com organizações seja para criar novas organizações, mudar organizações já existentes, trabalhar em organizações, investir em organizações ou, mais importante ainda, dirigir organizações.

Nesse contexto, é importante observar que a informação do comportamento organizacional é imprescindível para avaliar, fazer investimentos e alcançar retornos, ou para designar novas organizações que já existem. Assim sendo, o comportamento organizacional se distingue por ser um estudo científico aplicado por seguir uma abordagem contingencial, por aproveitar metodologia científica e amparando os indivíduos na resolução dos enigmas organizacionais pertinentes com as ciências sociais.

Daí se percebe o quão importante é conhecer e compreender o comportamento humano nas organizações, ainda mais se considerar que, na atual sociedade comercial, as pessoas são vistas como:

Pessoas e não como meros recursos da organização; fonte de impulso próprio que dinamizam a organização e não como agentes passivos, inertes e estáticos; parceiras ativas da organização e não como meros sujeitos passivos dela; elementos vivos e portadores de competências essenciais ao sucesso organizacional; o principal ativo organizacional que agrega inteligência ao negócio da organização (CHIAVENATO, 2010, p. 6).

Pelo exposto, é possível perceber que todo esforço do trabalho está modificando as pessoas nas organizações, marcadas por aspectos como variedades, novas habilidades e capacidades e diferentes valores sociais. As organizações e seus gerentes devem estar aptos para lidar com indivíduos de diferentes raças e origens, de diferentes idades, apoios culturais de diferentes aspectos e preferências dos modos de vida e valores pessoais.

O sucesso ou o fracasso da maioria dos projetos organizacionais depende do fator humano: é preciso saber lidar com pessoas de diferentes personalidades e saber se relacionar e comunicar com elas. Isso nada tem haver com os conhecimentos técnicos e especializados na formação de cada executivo, e sim com o desenvolvimento de habilidades no relacionamento interpessoal (CHIAVENATO, 2010, p. 6).

Nesse sentido, é possível inferir que o conhecimento técnico é capaz de alterar até certo ponto, porém, depois disso, as capacidades interpessoais se tornam imprescindíveis. Nesse sentido, deve-se ressaltar que há apenas pouco tempo, as escolas de Administração conseguiram restringir seus currículos focados apenas nas capacidades técnicas da administração, destacando economia, finanças, contabilidade, fazendo com que as produções técnicas viessem ser distintas da compreensão do desempenho humano na abrangência da eficiência e da eficácia entre as empresas.

O modelo de Comportamento Organizacional, depois de identificado, auxilia a organização a mostrar os pontos fortes e fracos, e permite desenvolver estratégias mais assertivas que diminuem ou até eliminem suas falhas (CHIAVENATO, 2010).

Porém, o comportamento organizacional se depara com desafios importantes: nas peculiaridades da força de trabalho que age nas empresas, nas perspectivas dos clientes e consumistas, nas competentes organizações, no comportamento dos chefes, e gerentes das organizações, principalmente, no caso do qual o conhecimento está se contornando progressivamente no fator de produção.

O comportamento organizacional compreende algumas variáveis, das quais é essencial fazer com que os modelos de comportamento organizacional tenham mais importância para o sucesso em geral. Destacam-se duas dessas: dependentes e independentes, de modo que a primeira envolve produção, absenteísmo, rotatividade, satisfação no trabalho (ROBBINS, 2010).

As variáveis independentes são constituídas por três níveis de análise que compreendem o sistema organizacional em geral, os grupos de pessoas e os indivíduos. Para o autor, as variáveis dependentes são compreendidas como fatores, os quais se pretende esclarecer ou prevenir e que são atingidos por outros fatores. Em influência, as mudanças independentes do comportamento provocam efeito no formato das variáveis dependentes.

A produtividade consiste nos resultados de uma empresa, a partir do alcance dos objetivos, por meio dos fatores de eficiência e de eficácia, de modo que a eficiência atende as necessidades do cliente com êxito, enquanto que a eficácia está relacionada aos resultados menores, de indivíduos e de grupos. Assim sendo, não se pode deixar de estabelecer uma relação entre comportamento organizacional e liderança.

\subsection{Liderança nas organizações}

A liderança está intimamente ligada ao aspecto grupal ou social, pois não se lidera a si mesmo, mas a um grupo de duas ou mais pessoas, a uma equipe. Robbins (2010) afirma que, no mundo dinâmico de hoje, as organizações precisam de liderança e de administração fortes para atingir o nível ótimo de eficácia.

A capacidade de liderar é inerente ao tipo de cargo ou profissão, encontra-se em todas as áreas da sociedade humana, pois:

[...] a capacidade de liderar é importante não apenas em estadistas, fundadores de nações ou dirigentes de religiões, mas também em treinadores de equipes esportivas, comandantes militares, regentes de orquestras, professores e todos os tipos 
de administradores de organizações (MAXIMIANO, 2009, p. 276-277)

Portanto, onde há atividade humana e relacionamento interpessoal, há espaço para a liderança, independentemente do tipo de relação, tamanho da organização, situação ou tarefa a ser cumprida.

Maxwell (2008) afirma que a liderança sempre faz muita diferença. A liderança requer muito das pessoas, é exigente e complexa. Kwasnicka (2003) salienta que a liderança estabelece objetivos, porém, ao fazê-lo, leva em consideração o que já foi previamente determinado pela organização. Assim, o líder é uma figura que conduz todos os demais rumo ao alcance das metas estabelecidas.

Cabe observar que o fato de a organização conferir a seus gestores autoridade formal não lhes garante uma capacidade de liderança eficaz. Portanto, não é o cargo que faz o líder, mas sim características, estilos ou mesmo situações em que a pessoa se encontra. Diante dessas afirmações se pode inferir que o processo de liderança nas organizações é complexo, envolve um grupo ou uma equipe de pessoas diferentes, exigindo do líder uma capacidade de articulação ou de influência sobre essas com o intuito de atingir uma meta ou objetivo preestabelecido (ROBBINS, 2010).

Conceituar liderança parece ser uma tarefa complexa e, até certo ponto, traiçoeira e delicada. Bergamini (2009) salienta que o estudo da liderança envolve aspectos que à primeira vista parecem contraditórios. Bryman (2004) afirma que a liderança é vista como processo pelo qual o líder se identifica para os subordinados, o que é importante, fornecendo um senso de direção e de propósitos por meio da articulação de uma visão de mundo convincente. Portanto, a liderança é a externalização das necessidades intrínsecas de um grupo que se personifica no líder.

Chu (2010), quando se refere ao sistema brasileiro de liderança, afirma que nas organizações dessa nação convivem perfis de liderança bastante distintos: o gestor mais tradicional, cujo perfil se calca no momento anterior à abertura econômica e a globalização (entre os anos de 1980 e 1990); e o gestor mais moderno, conectado à gestão de transformação e orientado às dimensões objetivas do negócio.

Portanto, os líderes brasileiros estão mudando sua postura em relação ao contexto que envolve a liderança, deixando de lado padrões paternalistas, migrando para um padrão de orientação voltado para o alcance das metas de autonomia e de independência dos liderados.

\subsubsection{Teorias sobre liderança}

Em se tratando de teorias sobre liderança, os vários autores pesquisados afirmam que são muitas e variadas, contemplando um momento histórico, e divididas em três categorias principais: teoria dos traços de personalidade; teoria de estilos de liderança; e teoria da liderança situacional (ROBBINS, 2010).
Bryman (2004) afirma que são quatro estágios da teoria e pesquisa sobre liderança, além das anteriores correntes citadas, o autor acrescenta a essas a abordagem da nova liderança (new leadership approach).

Bryman (2004) evidencia que o estudo da liderança está associado a um período específico, contendo nele aspectos próprios de cada época.

Bergamini (2009) salienta que, com o passar do tempo, o tema liderança significou diferentes construtos para diferentes pesquisadores, caminhando de estudos mais simples para investigações de maior complexidade.

Portanto, as teorias que se seguem são o resultado de anos de pesquisas sobre liderança e devem ser consideradas como uma sequência evolutiva. Novos aspectos do mesmo fenômeno foram sendo descobertos, os quais possibilitaram interpretações diferentes sem, no entanto, esgotar o assunto.

\subsubsection{Teoria dos traços de personalidade}

Para Bergamini (2009, p.10):

A teoria dos traços ficou assim conhecida porque seus pesquisadores propunham como ponto de partida que os líderes deveriam possuir determinados traços de personalidade especiais. Assim, 'a caracterização de um tipo especial de personalidade é que faria com que alguém se sobressaísse do grupo de pessoas comuns e pudesse exercer a sua ação como líder, em qualquer situação'.

Bryman (2004) afirma que essa orientação implica a crença de que a liderança é uma característica inata e não uma habilidade aprendida.

Ao analisar os traços pessoais, a maior parte desses recaiu sobre três grupos principais: traços físicos; habilidades; e características de personalidade. Robbins (2010) afirma que os traços podem auxiliar na identificação da liderança e que funcionam melhor para prever o surgimento da liderança do que para distinguir entre líderes eficazes e ineficazes.

Segundo Nogueira (2007, p.146): “essa teoria foi impulsionada pelas pesquisas que procuravam descrever o líder ideal por meio de determinados traços característicos".

Dessa forma, para ser líder o indivíduo deveria possuir alguns traços comuns a todos os líderes, inerentes a sua personalidade. Para Robbins (2010, p.361): “o fato de um indivíduo apresentar determinados traços e ser considerado líder pelos demais não significa, necessariamente, que será bem-sucedido em liderar seu grupo no alcance dos objetivos". Portanto, essa teoria auxilia na identificação da liderança e serve como referência para o início dos estudos sobre o tema.

Segundo Bryman (2004), a abordagem pessoal renasceu nos anos 1980 e, a partir dos anos 1990, houve mudança na ênfase dos estudos. Um estudo sobre os presidentes norteamericanos conclui que vários fatores de personalidade estavam relacionados à performance presidência (BRYMAN, 2004). Uma indicação maior do ressurgimento dessa abordagem é uma pesquisa de evidências com líderes reais bem-sucedidos, que conclui que tais líderes são fortemente 
motivados, têm forte desejo de comandar e exercer poder, além de demonstrar honestidade e integridade, e são dotados de forte autoconfiança (BRYMAN, 2004).

\subsubsection{Teorias de estilos de liderança}

Para Bryman (2004), a ênfase no estilo de liderança sinalizou uma mudança de foco, indo das características pessoais para o comportamento dos líderes. Bergamini (2009) salienta que, nessa segunda etapa das pesquisas sobre liderança, procurou-se descrever a forma como o líder se comporta, usando como metodologia a observação dos diferentes tipos de comportamentos adotados pelo líder. Para Robbins (2010), enquanto as teorias de traços forneciam uma base para selecionar a pessoa certa para exercer a função de líder, as teorias comportamentais sugeriam que é possível treinar pessoas para serem líderes.

Segundo Robbins (2010), os estudiosos da Universidade de Ohio e de Michigan propuseram duas dimensões comportamentais sobre liderança: o líder orientado para as pessoas, que enfatiza relações interpessoais por meio do interesse pessoal, pelas necessidades do funcionário e aceitação das diferenças pessoais entre os membros do grupo, e o líder orientado para a tarefa, que enfatiza os aspectos técnicos e práticos do trabalho, ou seja, revela uma preocupação direcionada à execução das tarefas e ao cumprimento das metas do grupo.

\section{Segundo Nogueira (2007, p.147)}

[...] um dos autores importantes dessa linha de estudos foi Rensis Likert, psicólogo e acadêmico da área de administração geral, conhecido pelas pesquisas sobre liderança. Likert definiu os estilos de liderança de acordo com os Sistemas Administrativos, baseado em quatro variáveis: tomada de decisão; sistema de comunicação; relacionamento interpessoal; e sistema de recompensas e punições. Suas conclusões determinaram quatro estilos de liderança: autoritária; benevolente; consultiva; e democrática ou participativa.

Bergamini (2009) afirma que a etapa de estudo coberta pela teoria dos estilos de liderança contou com trabalhos de pesquisa, que se desenvolveram em ambientes mais reais, uma vez que procuravam estudar pessoas que já ocupavam posição de liderança. Para Maximiniano (2010, p. 292), os críticos diziam que não há um estilo melhor que outro. A ideia de que a eficácia do estilo é condicionada pela situação resultou no desenvolvimento de diversas teorias da liderança situacional.

\subsubsection{Teoria da liderança situacional}

De acordo com Andrade e Amboni (2007, p. 108), os situacionistas não abandonaram, necessariamente, a procura de características significativas de líder, mas tentaram encontrá-las em situações que contenham elementos comuns. Maximiniano (2010, p.292) corrobora tal posicionamento, afirmando que o principal problema que a teoria da liderança situacional procura resolver é descobrir qual estilo se ajusta a qual situação.
De acordo com Nogueira (2007, p.146):

$\mathrm{Na}$ teoria situacional, há uma dinâmica entre a esfera da atuação do líder e a esfera da atuação dos liderados, ou seja, o líder modifica suas posições e estratégias, de acordo com situações influenciadas por diversos fatores contextuais, principalmente pela atuação dos liderados.

Portanto, em sua essência, a teoria da liderança situacional é mais complexa que as anteriores, não obstante possibilitar a exploração de variáveis que ainda não foram estudadas em profundidade.

Robbins (2010) salienta que a relação entre estilo de liderança e eficácia sugere que, sob uma condição A, o estilo $\mathrm{X}$ pode ser adequado; ao passo que o estilo $\mathrm{Y}$ é mais indicado para a situação B; e o estilo $\mathrm{Z}$ mais apropriado para a situação C. "Mas o que seriam essas situações? Uma coisa é dizer que a eficácia da liderança depende da situação, outra é identificar essas condições situacionais" (ROBBINS, 2010, p. 364).

A abordagem contingencial ainda tem considerável aceitação, apesar de a pesquisa por vezes sugerir que fatores situacionais não são sempre tão importantes quanto se imagina.

As abordagens contingenciais, provavelmente, se tornaram menos populares por conta de resultados inconsistentes (BRYMAN 2004). Com o intuito de analisar a situação em que ocorre a liderança, são apresentados a seguir alguns modelos, sendo esses: Modelo de Fiedler- Grau de Favorabilidade e Modelo de Hersey e Blanchard.

Segundo Maximiano (2010, p.292-293):

Fiedler entende que as situações que os líderes enfrentam podem ser avaliadas em termos de três características: as relações entre o líder e os seguidores; o grau de estruturação da tarefa; e o poder da posição. Portanto, se a relação entre líder e seguidores for positiva, a situação é favorável. Se o grau de organização for alto, também a liderança será favorável. Porém, se a tarefa for imprevisível, há desfavorabilidade para o líder. E, por último, se o líder não tiver poder, a situação é desfavorável. Destarte, a maturidade do subordinado, avaliada em termos de grau de capacidade e interesse de fazer um bom trabalho, é a principal característica da situação que qualquer líder enfrenta. Quanto mais maduro o seguidor, menos intenso deve ser o uso da autoridade pelo líder e mais intensa a orientação para o relacionamento. Portanto, salientando a maturidade do subordinado, Hersey e Blanchard dividem a liderança em quatro estilos ou formas, denominando-as de: comando; venda; participação; e delegação.

No estilo 1 (comando), o líder assume o papel de dar ordens e reduzir o apoio emocional. Isso ocorre por dois motivos: a baixa maturidade dos subordinados e a pouca ênfase no relacionamento.

No estilo 2 (venda) se observa o oposto, um alto nível de comportamentos orientados para a tarefa e o relacionamento, simultaneamente. Assim, o líder precisa ser, ao mesmo tempo, diretivo e apoiador. No estilo 3 (participação), a orientação é o relacionamento em detrimento da tarefa. No estilo 4 (delegação), há pouca atenção, tanto na tarefa, quanto no relacionamento.

Como foi salientado anteriormente, a relação entre 
comportamento organizacional e liderança é estreita, um laço necessário nas organizações. Acredita-se que as relações humanas, no ambiente de trabalho, estão inseridas nessa teia do comportamento organizacional.

\section{Conclusão}

Ao abordar a temática: Comportamento Organizacional e Liderança é impreterível abordar as relações de pessoas, no ambiente organizacional, uma vez que este é composto por pessoas, dando-lhe vida e personalidade própria, porém a maneira através da qual as pessoas se comportam, tomam decisões, trabalham, varia de diferentes formas, sendo que tal variação vai depender, em sua maioria, das políticas e diretrizes das organizações na maneira como lidar com as pessoas em suas atividades.

Não há como uma organização conseguir seus objetivos, suas metas, sem que exista um relacionamento harmonioso, capaz de superar as discórdias e os conflitos, que consiga fazer das desavenças uma oportunidade de estreitar as relações e adicionar a habilidade de resolução dos problemas. Desse modo, são elas, as pessoas, por meio de seu comportamento, que atuando dentro de uma organização, terminam moldando a própria forma de agir da organização.

Para mobilizar e utilizar toda a capacidade das pessoas, em suas atividades, as organizações têm buscado modificar seus conceitos, alterando suas práticas gerenciais, investindo diretamente nas pessoas, que entendem dos produtos e serviços em vez de focar somente nos clientes.

Nesse sentido, conclui-se que a figura do líder é fundamental dentro desses arranjos do comportamento organizacional, liderando as pessoas, as equipes para que essas possam desenvolver suas atividades em consonância com os interesses da organização.

\section{Referências}

ANDRADE, R.O.B.; AMBONI, N. Teoria geral da administração: das origens às perspectivas contemporâneas. São Paulo: M. Books do Brasil, 2007.

BERGAMINI, C.W. Liderança: administração do sentido. São Paulo: Atlas, 2009.

BRYMAN, A. Liderança nas organizações. Handbook de Estudos Organizacionais. São Paulo, Atlas, 2004.

CHIAVENATO, I. Comportamento organizacional. Rio de Janeiro: Elsevier, 2010.

CHU, R.A. Modelo contemporâneo da gestão à brasileira. São Paulo: Cengage Learning, 2010.

CHU, R.A. Recursos humanos. São Paulo: Campus, 2009.

MAXIMIANO, A.C.A. Introdução à administração. São Paulo: Atlas, 2009.

MAXIMIANO, A.CA. Teoria geral da administração: da escola científica à competitividade na economia globalizada. São Paulo: Atlas, 2009.

MAXIMIANO, A.C.A. Administração de projetos: como transformar ideias em resultados. São Paulo: Atlas, 2009.

MAXIMIANO, A.C.A. Teoria geral da administração: da revolução urbana à revolução digital. São Paulo: Atlas, 2010.

NOGUERIA, A.J.F.M. As pessoas na organização. São Paulo: Gente, 2007.

ROBBINS, S.; JUDGE, T.A.; SOBRAL, F. Comportamento organizacional. São Paulo: Pearson Prentice Hall, 2010.

MAXWELL, J.C. O livro de ouro da liderança: o maior treinador de líderes da atualidade apresenta as grandes lições de liderança que aprendeu na vida. Rio de Janeiro: Thomas Nelson Brasil, 2008.

KWASNICKA, E.L. Teoria geral da administração: uma síntese. São Paulo: Atlas, 2003. 